\title{
Bacteroides fragilis enterotoxin upregulates lipocalin-2 expression in intestinal epithelial cells
}

\author{
Do Young Yoo ${ }^{1, *}$, Su Hyuk Ko ${ }^{1, *}$, Jireh Jung ${ }^{1}$, Young-Jeon $\mathrm{Kim}^{2}$, Joo Sung $\mathrm{Kim}^{3}$ and Jung Mogg Kim ${ }^{1}$
}

Enterotoxigenic Bacteroides fragilis (ETBF) produces an $\sim 20 \mathrm{kDa}$ B. fragilis enterotoxin (BFT), which plays an essential role in mucosal inflammation. Lipocalin (LCn)-2, a siderophore-binding antimicrobial protein, is critical for control of bacterial infection; however, expression of Lcn-2 in BFT-exposed intestinal epithelial cells has not been elucidated. In the present study, stimulation of human intestinal epithelial cells with BFT resulted in the upregulation of Lcn-2 expression that was a relatively late response of intestinal epithelial cells compared with human $\beta$-defensin (hBD)-2 expression. The upregulation of Lcn-2 was dependent on AP-1 but not on NF- $\kappa$ B signaling. Lcn- 2 induction via AP-1 was regulated by mitogenactivated protein kinases (MAPKs) including ERK and p38. Lcn-2 was secreted from the apical and basolateral surfaces in BFT-treated cells. These results suggest that a signaling pathway involving MAPKs and AP-1 is required for Lcn-2 induction in intestinal epithelial cells exposed to BFT, after which the secreted Lcn-2 may facilitate antimicrobial activity within ETBF-infected mucosa.

Laboratory Investigation (2013) 93, 384-396; doi:10.1038/labinvest.2013.1; published online 4 February 2013

KEYWORDS: AP-1; Bacteroides fragilis enterotoxin; intestinal epithelial cells; mitogen-activated protein kinase

Enterotoxigenic Bacteroides fragilis (ETBF) strains are known to be associated with intestinal diseases such as diarrheal illness, colitis, inflammatory bowel disease (IBD) ${ }^{1,2}$ and colorectal cancer. $^{3-5}$ B. fragilis enterotoxin (BFT), an $\sim 20 \mathrm{kDa}$ heat-labile metalloprotease, is regarded as a virulence factor for these diseases. To reduce or prevent intestinal infection, the luminal flora and invading pathogens can induce production of epithelial-derived antimicrobial factors such as defensins, cathelicidin LL-37, and antimicrobial proteins. ${ }^{6-9}$ Recently, we demonstrated that stimulation of intestinal epithelial cells with BFT enhanced the expression of the antibacterial peptide human $\beta$-defensin (hBD)-2. ${ }^{10}$ However, it is possible that other antibacterial factors may be upregulated in the ETBF-infected area of the intestine and contribute to regulation of enteric inflammation.

Although ETBF strains are considered to be enteric pathogens, clinical studies have routinely identified asymptomatic stool carriage of ETBF in a substantive portion (4-20\%) of control populations. ${ }^{11,12}$ In addition, colonization of gnotobiotic mice with ETBF was shown to induce acute colitis. ${ }^{13,14}$ In contrast, conventional mice colonized with ETBF have been shown to develop rapidonset, transient diarrhea lasting 3 to 4 days. Subsequently, conventional mice colonized with ETBF exhibit persistent, asymptomatic colonization, with ongoing histopathologic colitis presenting for as long as 16 months. ${ }^{5,14,15}$ These reports suggest that induced antimicrobial factors may play a role in the growth inhibition of commensal bacteria, resulting in the survival of colonized ETBF in the gut.

For iron acquisition, microbes use an array of iron chelators known as siderophores. ${ }^{16}$ Bacterial siderophores are scavenged by lipocalin-2 (Lcn-2; also known as neutrophil gelatinase-associated lipocalin (NGAL) or siderocalin) as part of the innate immune defense. ${ }^{17} \mathrm{Lcn}-2$ exerts its growthinhibitory effect by binding several ferric siderophore complexes such as siderophore enterobactin (Ent), which is produced by Gram-negative enteric bacteria, including Escherichia coli, Salmonella enterica, and Klebsiella pneumoniae. ${ }^{18,19}$ Besides working as a bacteriostatic protein, Lcn-2 has been reported to be involved in the pathogenesis of

\footnotetext{
${ }^{1}$ Department of Microbiology and Department of Biomedical Science, Hanyang University College of Medicine and Graduate School of Biomedical Science and Engineering, Seoul, Korea; ${ }^{2}$ Department of Biotechnology, Joongbu University, Choongnam, Korea and ${ }^{3}$ Department of Internal Medicine and Liver Research Institute, Seoul National University College of Medicine, Seoul, Korea

Correspondence: Professor/Dr Jung Mogg Kim, MD, PhD, Department of Microbiology, Hanyang University College of Medicine, 17 Haengdang-dong, Sungdong-gu, Seoul, 133-791, Korea.

E-mail: jungmogg@hanyang.ac.kr

*The first two authors contributed equally to this work.
}

Received 13 July 2012; revised 11 December 2012; accepted 19 December 2012 
inflammation and cancer. ${ }^{20}$ In light of these reports, it is possible that Lcn-2 may affect inflammatory responses induced by ETBF-derived BFT and subsequently contribute to host defense. However, little is known about the regulation of Lcn-2 expression in response to BFT stimulation.

Activation of mitogen-activated protein kinases (MAPKs) and nuclear factor- $\kappa \mathrm{B}(\mathrm{NF}-\kappa \mathrm{B})$ is critical for the induction of Lcn-2 in several cell lines. ${ }^{21-24}$ In addition, it is possible that activator protein-1 (AP-1) may be involved in the Lcn-2 induction process as the Lcn-2 gene promoter contains binding sites for both AP- 1 and NF- $\kappa \mathrm{B}$; however, there are no reports regarding AP-1-induced Lcn-2 expression in the literature. Moreover, there is no evidence of BFT-induced MAPKs or AP-1 activation leading to Lcn-2 expression, although those signaling molecules have been reported to be activated in intestinal epithelial cells exposed to BFT. ${ }^{10,25-31}$ In the studies reported here, we investigated the regulation of Lcn-2 expression in response to BFT stimulation, and found that stimulation with BFT upregulates Lcn-2 expression in intestinal epithelial cells through the activation of MAPKs and the AP-1 signaling pathway.

\section{MATERIALS AND METHODS Reagents}

Lipopolysaccharide (LPS)-free fetal bovine serum (FBS), $\mathrm{Ca}_{2}{ }^{+}$and $\mathrm{Mg}_{2}{ }^{+}$-free Hanks' balanced salt solution (HBSS), antibiotics, L-glutamin, and Trizol were obtained from GIBCO BRL (Gaithersburg, MD, USA). Dulbecco's modified Eagle's medium (DMEM), Ham's F12 medium, dithiothreitol (DTT), and EDTA were purchased from Sigma Chemical (St Louis, MO, USA). Monoclonal antibodies (mAbs) against $\mathrm{I} \kappa \mathrm{B} \alpha$, phospho-I $\kappa \mathrm{B} \alpha$, pan-ERK1/2 (p44/p42), phospho-ERK1/2, pan-JNK (p54/p46), phospho-JNK, pan-p38, phospho-p38, phospho-p65, glyceraldehyde 3-phosphate dehydrogenase (GAPDH), and actin were acquired from Cell Signaling Technology (Beverly, MA, USA). Goat anti-rabbit and anti-mouse secondary Abs conjugated to horseradish peroxidase were purchased from Transduction Laboratories (Lexington, KY, USA). Abs against c-Jun, c-Fos, Jun-B, Jun-D, and Fos-B were obtained from Santa Cruz Biotechnology (Santa Cruz, CA, USA). PD98059, SB203580, and SP600125 were acquired from Calbiochem (La Jolla, CA, USA). To inhibit the AP-1 activity, SR11302 (Tocris Bioscience, Ellisville, MO, USA) was used. ${ }^{32}$

\section{Purification of BFT and Cell Culture Conditions}

BFT was purified from the culture supernatant of a highly toxigenic ETBF strain as described previously. ${ }^{10,25-30,33}$ BFT preparation purity was confirmed by sodium dodecyl sulfatepolyacrylamide gel electrophoresis (SDS-PAGE). Typical preparations of BFT contained $0.5-1.2 \mathrm{mg}$ protein $/ \mathrm{ml}$ as measured by the BCA protein assay. Buffers used in the purification were prepared using LPS-free water. LPS activity in the BFT solution $(1 \mathrm{mg} / \mathrm{ml})$ was less than one endotoxin unit/ml by quantitative chromogenic limulus amebocyte lysate (BioWhittaker, Walkersville, MD, USA). BFT was frozen in aliquots at $-80{ }^{\circ} \mathrm{C}$ immediately after purification.

The human colon adenocarcinoma cell line HT-29 (ATCC HTB 38) was grown in DMEM with $10 \%$ FBS, $2 \mathrm{mM}$ glutamine and antibiotics. Cells were seeded at $0.5-2 \times 10^{6}$ cells per well in six-well plates and allowed to attach overnight. After $12 \mathrm{~h}$ of serum starvation, cells were incubated with BFT for the indicated period.

T84 human colon epithelial cells (ATCC CCL-248) were cultured in 50\% DMEM $/ 50 \%$ Ham's F12 medium supplemented with 5\% FBS, $2 \mathrm{mM}$ glutamine, and antibiotics. The polarized monolayers of T84 cells were prepared by seeding $5 \times 10^{5}$ cells on collagen-coated microporous supports $(3-\mu \mathrm{m}$ pore size, $1.12-\mathrm{cm}^{2}$ growth area) in transwell chambers (Corning Costar, Lowell, MA, USA) as previously described. ${ }^{30}$ The formation of tight junctions was functionally assessed by measuring the electrical resistance across the monolayers (transepithelial electrical resistance (TER)) using a Millicell electrical resistance system (Millipore, Bedford, MA, USA).$^{30}$ The electrical resistance of the unstimulated control in this study was $>1000 \Omega \times \mathrm{cm}^{2}$ after subtraction of the resistance across a cell-free filter. To confirm the tight junction, $\left[{ }^{3} \mathrm{H}\right]$-inulin flux across the monolayers in a transwell chamber was measured as described previously. ${ }^{34}$ Briefly, monolayers of T84 cells were grown on transwells for 4-16 days and were washed twice in HBSS before the addition of $\left[{ }^{3} \mathrm{H}\right]$-inulin $(2.5 \mu \mathrm{Ci} / \mathrm{ml}$, PerkinElmer, Boston, MA, USA) in HBSS to the top well (basolateral side) and nonradioactive HBSS to the bottom well (apical side). After $3 \mathrm{~h}$, $10 \mu \mathrm{l}$ was sampled from the bottom well and counts per min (c.p.m.) were measured using a scintillation counter. Data are presented in triplicate as a percentage of the amount of c.p.m. added to the top chamber.

\section{Isolation of Primary Human Intestinal Epithelial Cells}

Primary human colon epithelial cells were obtained from normal-appearing mucosa of surgically resected colons from patients with colon cancer, as described previously. ${ }^{26,28,35,36}$ The study was approved by the Ethics Committee of Seoul National University Hospital. After the surgical specimens were washed twice in HBSS, the epithelia were removed by scraping the surface with a glass slide. The scraped tissue was cut into small sections using a razor blade and washed at room temperature with $10 \mathrm{mM}$ DTT in HBSS for $30 \mathrm{~min}$, followed by two 90-min washes with $1 \mathrm{mM}$ EDTA. Cells liberated from both washes were harvested by centrifugation at $500 \mathrm{~g}$ for $5 \mathrm{~min}$ at room temperature, followed by incubation with $3 \mathrm{mg} / \mathrm{ml}$ dispase and $1 \mathrm{mg} / \mathrm{ml}$ DNase at $37^{\circ} \mathrm{C}$ for $30 \mathrm{~min}$. Cells were harvested by centrifugation, followed by further purification using a Percoll density gradient (Pharmacia Biotech, Uppsala, Sweden), where the intestinal epithelial cells are located at the $0-30 \%$ layer interface. After centrifugation for $20 \mathrm{~min}$ at $300 \mathrm{~g}$, purified epithelial cells were collected. The freshly isolated colon epithelial cells were cultured at a density of $2 \times 10^{6}$ cells $/ \mathrm{ml}$ in 
RPMI-1640 media supplemented with 10\% FBS, $2 \mathrm{mM}$ glutamine, and antibiotics $(100 \mathrm{U} / \mathrm{ml}$ of penicillin and $100 \mu \mathrm{g} / \mathrm{ml}$ of streptomycin). Epithelial cell preparations contained $<5 \%$ contamination from B cells or monocytes/ macrophages, as assessed by flow cytometry using CD19/20 and CD14 as markers.

\section{Quantitative Reverse Transcriptase (RT)-PCR and ELISA}

After cells were treated with BFT, total cellular RNA was extracted using Trizol. Reverse transcription and PCR amplification were performed as described previously. ${ }^{37}$ The primers and expected PCR product sizes were as follows: Lcn-2, 5'-TCACCTCCGTCCTGTTTAGG- $3^{\prime}$ (sense) and $5^{\prime}$-CGAAGTCAGCTCCTTGGTTC-3' (antisense), $242 \mathrm{bp}$ (NM_005564.3 Homo sapiens lipocalin 2 (Lcn-2), mRNA); hBD-2, 5'-CCAGCCATCAGCCATGAGGGT-3' (sense) and $5^{\prime}$-GGAGCCCTTTCTGAATCCGCA-3' (antisense), $255 \mathrm{bp}$ (NM_004942.2 Homo sapiens defensin, $\beta 4$ A (DEFB4A), mRNA); and human $\beta$-actin, $5^{\prime}$-TGACGGGGTCACCCACA CTGTGCCCATCTA- $3^{\prime}$ (sense) and $5^{\prime}$-CTAGAAGCATTGCG GTGGACGATGGAGGG-3' (antisense), 661 bp (NM_001101.3 Homo sapiens actin, $\beta$ (ACTB), mRNA). To quantify mRNA transcripts, RNA standards for Lcn-2 and hBD-2 were generated by in vitro transcription using T7 RNA polymerase as described previously. ${ }^{10,37}$ Dr Martin F Kagnoff of the University of California, San Diego, kindly provided standard RNA for human $\beta$-actin. The sizes of the PCR products generated from the standard RNAs for Lcn-2, hBD-2, and human $\beta$-actin were 348,371 , and $520 \mathrm{bp}$, respectively.

The amount of Lnc- 2 and hBD-2 in culture supernatants was measured with a commercially available enzyme-linked immunosorbent assay (ELISA; Phoenix Pharmaceuticals, Belmont, CA, USA) according to the manufacturer's instructions. One experiment was performed in triplicate wells.

\section{Electrophoretic Mobility Shift Assay}

Cells were harvested and nuclear extracts prepared as described previously. ${ }^{30}$ Protein concentration in the extracts was determined by Bradford assay (Bio-Rad, Hercules, CA, USA). Electrophoretic mobility shift assay (EMSA) was performed according to the manufacturer's instructions (Promega, Madison, WI, USA). In brief, $5 \mu \mathrm{g}$ of nuclear extract was incubated for $30 \mathrm{~min}$ at room temperature with a $\gamma^{32}$ P-labeled oligonucleotide probe $\left(5^{\prime}\right.$-AGTTGAGGGGACTT TCCCAGGC- $3^{\prime}$ for the NF- $\kappa$ B binding site; $5^{\prime}$-CGCTTGA TGACTCAGCCGGAA- $3^{\prime}$ for the AP-1 binding site). After incubation, both bound and free DNA was resolved on 5\% polyacrylamide gels, as described previously. ${ }^{30}$ To identify the specific members of the AP-1 family activated by BFT stimulation, a supershift assay was performed as described above, except that rabbit antibodies $(1 \mu \mathrm{g} /$ reaction $)$ against c-Jun, c-Fos, Jun-B, Jun-D, and Fos-B were added during the binding reaction period. ${ }^{26}$

\section{Plasmids, Transfection, and Luciferase Assays}

Wild-type Lcn-2 plasmid [pNGAL(-900)-luc] and wild-type hBD-2 plasmid (hBD-2-2338-luc) was kindly donated by Dr Tatsushi Muta or the Laboratory of Cell Recognition and Response, Graduate School of Life Sciences, Tohoku University, Japan, ${ }^{24}$ and Dr Jürgen Harder of the Clinical Research Unit, Department of Dermatology, University Hospital Kiel, Germany, ${ }^{38}$ respectively. The reporter plasmid containing AP-1-luciferase was purchased from BD Sciences (Franklin Lakes, NJ, USA). ${ }^{26}$ Dr Martin F Kagnoff of the University of California, San Diego, kindly provided the $\mathrm{p} 2 \mathrm{x}$ $\mathrm{NF}-\kappa \mathrm{B}$-, $\mathrm{p} \beta$-actin-, and $\mathrm{pRSV}-\beta$-galactosidase transcriptional reporters. ${ }^{39}$ To analyze promoter activity, cells in six-well dishes were transfected with $1.5 \mu \mathrm{g}$ plasmid DNA using FuGene6 transfection reagent (Roche, Mannheim, Germany). The transfected cells were incubated for $24 \mathrm{~h}$ at $37^{\circ} \mathrm{C}$ in a $5 \%$ $\mathrm{CO}_{2}$ incubator and were then treated with BFT for the indicated time in the figure legends. Luciferase activity was determined in accordance with the manufacture's instructions (Tropix, Bedford, MA, USA). Light release was quantitated for $10 \mathrm{~s}$ using a luminometer (MicroLumat Plus, Berthold, Bad Wildbad, Germany) as previously described. ${ }^{37}$

TAM-67 is a dominant-negative c-Jun super-repressor that lacks the transactivation domain of c-Jun and is a potent inhibitor of AP-1-mediated transactivation. ${ }^{36,40}$ TAM-67 dimerizes with c-Jun or c-Fos family members and binds DNA, resulting in the inhibition of wild-type c-Jun and c-Fos function. The TAM-67 used in the present study was a gift from Dr Andreas von Knethen of the University of Erlangen (Erlangen, Germany). Small interfering RNA (siRNA) against the NF- $\kappa \mathrm{B}$ p65 subunit was designed as previously described. ${ }^{10}$ The siRNAs and nonsilencing negative control siRNAs were synthesized by QIAGEN (Valencia, CA, USA). Transfection of the dominant-negative super-repressor or siRNA into cells was performed as described previously. ${ }^{41}$ Cells were cultured in 6-well plates to $50-80 \%$ confluence and the cells were then transfected with the dominant-negative super-repressor, siRNA, or nonsilencing siRNA using Fugene 6 (Roche) as a transfection reagent. Briefly, $1 \mu \mathrm{g}$ of siRNA or $1.5 \mu \mathrm{g}$ plasmid DNA was diluted in serum-free medium to produce a final volume of $100 \mu \mathrm{l}$ to which $3 \mu \mathrm{l}$ of Fugene 6 was added before the mixture was incubated for $15 \mathrm{~min}$ at room temperature. The transfection mixture was added to wells that each contained $300 \mu \mathrm{l}$ of medium (10\% FBS content). Transfected cells were incubated for $48 \mathrm{~h}$ before the assay.

A retroviral system containing a mammalian expression vector encoding a hemagglutinin (HA) epitope-tagged mutant $\mathrm{I} \kappa \mathrm{B} \alpha(\mathrm{I} \kappa \mathrm{B} \alpha-\mathrm{AA})$ with serine for alanine amino acid substitutions at positions 32 and 36 was used to block NF- $\kappa \mathrm{B}$ activation as described previously. ${ }^{35}$ Recombinant adenoviruses containing dominant-negative MEK-1 (ADV-118) and dominant-negative p38 $\alpha$ (ADV-105) expression vectors were obtained from Cell BioLabs (San Diego, CA, USA). The MEK1 adenoviral mutant cannot be phosphorylated, as the 
dual phosphorylation site S217/S221 was altered to A217/ A221. In the dominant-negative $\mathrm{p} 38 \alpha$ plasmid, the TGY dual phosphorylation site was substituted with AGF. ${ }^{36}$

\section{Immunoblots}

Cells were washed with ice-cold PBS and lysed by addition of $0.5 \mathrm{ml} /$ well lysis buffer $(150 \mathrm{mM} \mathrm{NaCl}, 20 \mathrm{mM}$ Tris $\mathrm{pH} 7.5$, $0.1 \%$ Triton X-100, $1 \mathrm{mM}$ PMSF, and $10 \mu \mathrm{g} / \mathrm{ml}$ aprotonin). Protein was size-fractionated on a $6 \%$ polyacrylamide minigel (Mini-PROTEIN II; Bio-Rad), with $15-50 \mu \mathrm{g}$ of protein loaded per lane, and electrophoretically transferred to a PDVE membrane $(0.45-\mu \mathrm{m}$ pore size). The immunoreactive proteins to which the primary antibodies had bound were visualized using goat anti-rabbit or anti-mouse secondary antibodies conjugated to horseradish peroxidase, followed by enhanced chemiluminescence (ECL system; Amersham Life Science, Buckinghamshire, UK) and exposure to X-ray film.

\section{In Vitro Kinase Assays}

FACE ERK1/2, FACE p38, FACE JNK, TransAM NF- $\kappa$ B, and TransAM AP-1 ELISA kits were obtained from Active Motif (Carlsbad, CA, USA). Each assay was performed according to the manufacturer's instructions. ${ }^{33,36,42}$ One experiment was performed in triplicate wells and all experiments were repeated more than three times.

\section{Statistical Analyses}

Data are presented as the mean \pm s.d. for quantitative RT-PCR and the mean \pm s.e.m. for ELISA, luciferase assays, and kinase assays. Wilcoxon's rank-sum test was used for statistical analysis. The $P$-values of $<0.05$ were considered statistically significant.

\section{RESULTS \\ BFT Induces Lcn-2 Expression in Intestinal Epithelial Cells}

Stimulation of HT-29 cells with BFT increased the expression of Lcn-2 mRNA transcripts, in which significant Lcn-2 mRNA upregulation began at $9 \mathrm{~h}$ after stimulation and continued to increase over the ensuing $48 \mathrm{~h}$ (Figure 1a). Similar kinetics of Lcn-2 mRNA expression wee obtained following BFT stimulation of primary human intestinal epithelial cells (Figure 1b). The magnitude of Lcn-2 expression was dependent on the concentration of stimulated BFT (Figure 1c). Based on this result, $100 \mathrm{ng} / \mathrm{ml}$ of BFT was used in the next experiments. To confirm that the expressed Lcn-2 transcripts were linked to protein synthesis, we measured the production of Lcn-2 protein in culture supernatants. As shown in Figure 1d, stimulation of HT-29 and T84 cells with BFT resulted in increased Lcn-2 release. Similar results were also observed in primary human intestinal epithelial cells stimulated with BFT.

\section{NF- $\kappa$ B Activation Does Not Lead to Lcn-2 Expression in Intestinal Epithelial Cells Stimulated with BFT}

As promoters for Lcn-2 gene induction contain binding sites for NF- $\kappa \mathrm{B}$, we asked whether BFT-induced NF- $\kappa \mathrm{B}$ activation could be associated with Lcn-2 expression. DNA binding studies with NF- $\kappa \mathrm{B}$ showed that stimulation with BFT increased NF- $\kappa$ B DNA binding in HT-29 cells (Figure 2a). Activation of NF- $\kappa$ B signal was first apparent 10 min after stimulation, peaked at $1-3 \mathrm{~h}$, and decreased to baseline levels over the ensuing $24 \mathrm{~h}$. Concurrently, an increase of phospho$\mathrm{I} \kappa \mathrm{B} \alpha$ and the degradation of $\mathrm{I} \kappa \mathrm{B} \alpha$ were observed in BFT-stimulated cells, with the signals having almost recovered to baseline level $24 \mathrm{~h}$ after stimulation.

A retrovirus containing dominant-negative $\mathrm{I} \kappa \mathrm{B} \alpha$ (retrovirus- $\mathrm{I} \kappa \mathrm{B} \alpha-\mathrm{AA}$ ) was used to suppress NF- $\kappa \mathrm{B}$ activity. Transfection with retrovirus-I $\kappa \mathrm{B} \alpha-\mathrm{AA}$ completely blocked NF- $\kappa$ B binding in BFT-stimulated HT-29 cells, and the control retrovirus containing a GFP plasmid (retrovirus$G F P$ ) did not reduce NF- $\kappa \mathrm{B}$ binding (Figure $2 \mathrm{~b}$ ). In this experimental condition, the level of Lcn-2 mRNA was determined by quantitative RT-PCR. Transfection with retrovirus- $\mathrm{I} \kappa \mathrm{B} \alpha-\mathrm{AA}$ did not significantly inhibit Lcn-2 mRNA expression in HT-29 cells stimulated with BFT (Figure 2c). In contrast, suppression of NF- $\kappa \mathrm{B}$ activity resulted in the obvious inhibition of hBD-2 mRNA levels (Figure 2d). Consistent with this, BFT-induced Lcn-2 secretion was not significantly changed when the NF- $\kappa \mathrm{B}$ signal was blocked (Figure 3a). hBD-2 secretion as the positive control was significantly decreased in retrovirus-I $\kappa \mathrm{B} \alpha$-AA-transfected cells compared with untransfected or retrovirus-GFPtransfected cells treated with BFT.

To confirm the NF- $\kappa \mathrm{B}$-independent expression of Lcn-2 in response to BFT stimulation, we performed another experiment using p65 siRNA to suppress the NF- $\kappa \mathrm{B}$ signal. Blocking NF- $\kappa$ B with $p 65$ siRNA did not significantly change the BFT-induced increase in the promoter activity of Lcn-2 (Figure $3 \mathrm{~b}$ ). Consistent with this, mRNA expression and protein secretion of Lcn-2 induced by BFT stimulation did not show significant differences between p65 siRNA-transfected and untransfected cells (Figures $3 \mathrm{c}$ and d). In this system, nuclear phospho-p65 signal induced by BFT was completely suppressed in HT-29 cells transfected with p65 siRNA (Figure 3e). These results do not demonstrate a direct connection between NF- $\kappa$ B signaling and Lcn-2 induction in BFT-stimulated intestinal epithelial cells.

\section{AP-1 Is Involved in the Induction of the Len-2 Gene in BFT-Stimulated Intestinal Epithelial Cells}

We next evaluated whether Lcn-2 induction might be associated with AP-1 signaling in intestinal epithelial cells stimulated with BFT as promoters for Lcn-2 gene induction contain binding sites for AP-1. BFT stimulation increased the DNA binding activity of AP-1 in HT-29 cells (Figure 4a). A supershift assay was performed to identify the specific AP-1 subunits that comprise the AP-1 signal detected by EMSAs in 

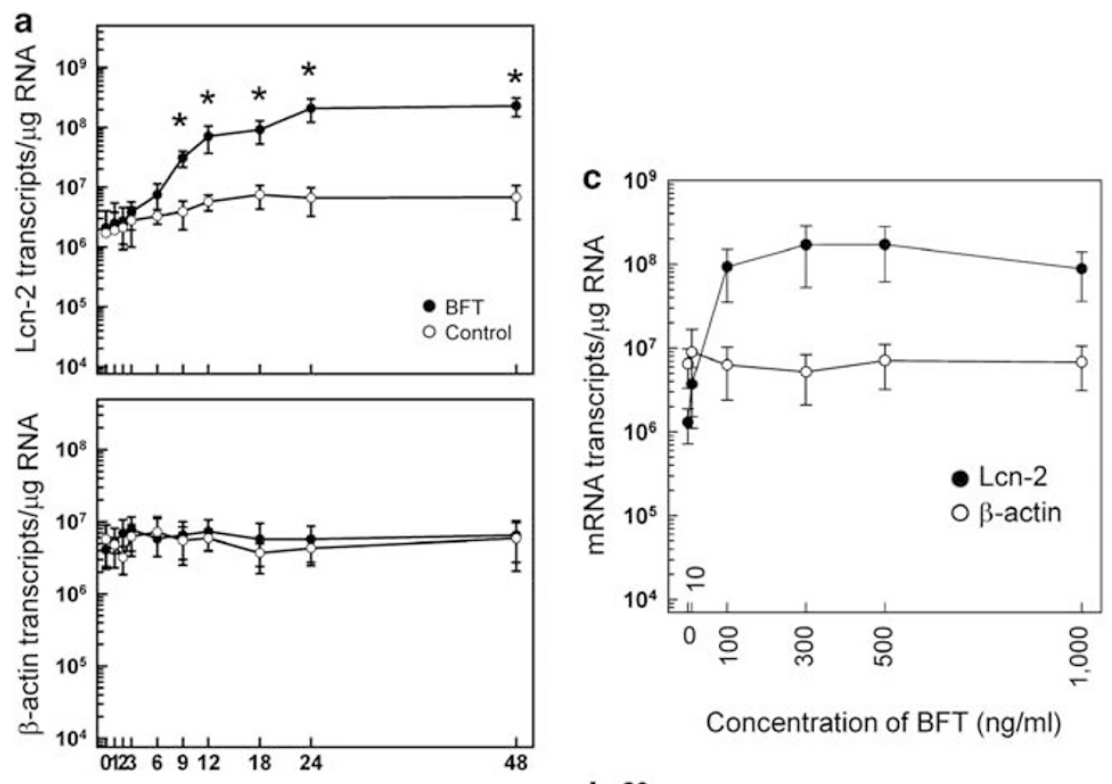

Concentration of BFT (ng/ml)
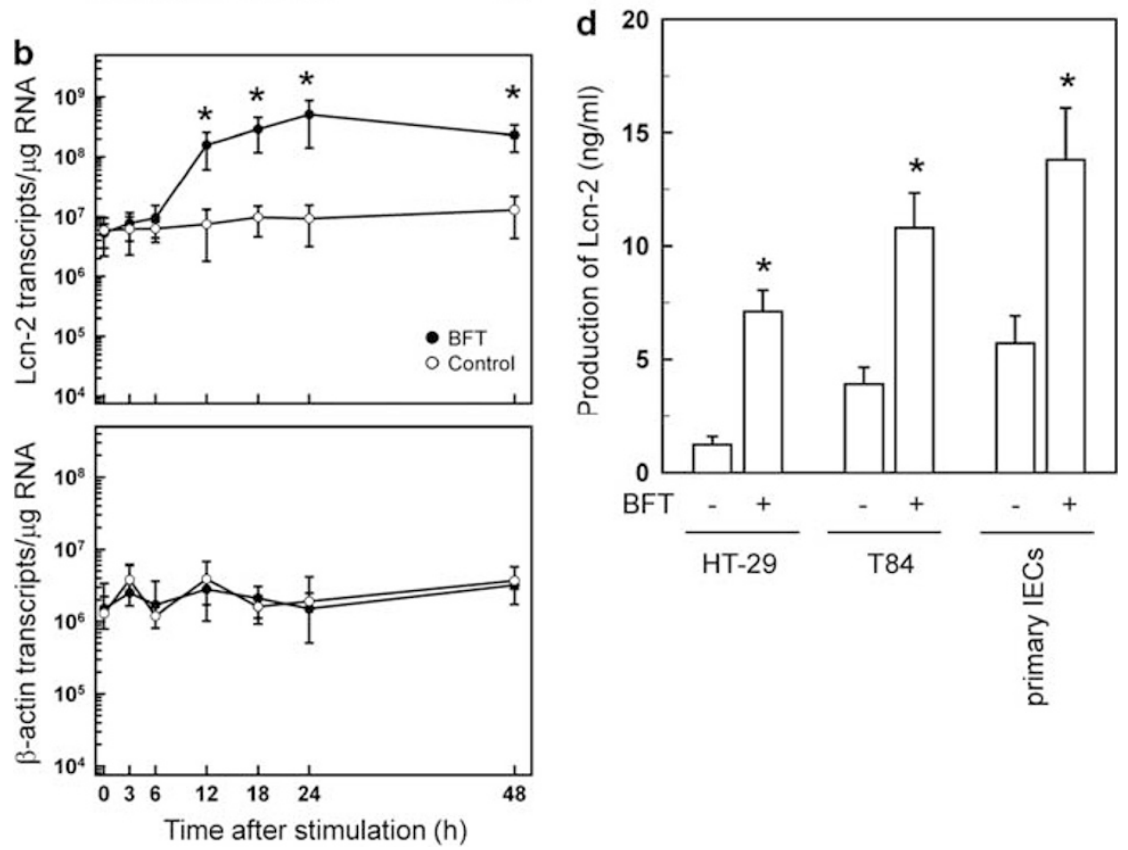

Figure 1 Expression of Lcn-2 in intestinal epithelial cells after BFT treatment. (a, b) Time courses of Lcn-2 mRNA expression in intestinal epithelial cells after treatment with BFT. (a) HT-29 cells were treated with BFT $(100 \mathrm{ng} / \mathrm{ml})$ for the indicated periods of time. Levels of Lcn-2 and $\beta$-actin mRNA were analyzed by quantitative RT-PCR using each standard RNA. The values are expressed as the mean \pm s.d. $(n=5)$. (b) Primary intestinal epithelial cells were treated with BFT $(100 \mathrm{ng} / \mathrm{ml})$ for the indicated periods of time. The values are expressed as the mean \pm s.d. ( $(n=3)$. (c) HT-29 cells were treated with the indicated concentrations of BFT for $18 \mathrm{~h}$. mRNA expression of Lcn-2 (closed circle) and $\beta$-actin (open circle) was analyzed by quantitative RT-PCR using each standard RNA. The values are expressed as the mean \pm s.d. $(n=5)$. (d) HT-29, T84, and primary human intestinal epithelial cells were treated with BFT $(100 \mathrm{ng} / \mathrm{ml})$ for $24 \mathrm{~h}$. The concentration of Lcn-2 protein in culture supernatants was determined by ELISA (mean \pm s.e.m., $n=5$ ). ${ }^{*} P<0.05$ versus untreated controls.

BFT-stimulated cells. As shown in Figure 4b, the entire AP-1 signal disappeared with the treatment of Abs to c-Jun and c-Fos. However, the addition of other Abs to Jun B, Jun D, and FosB did not affect the AP-1 signal induced by BFT.

To suppress the activated AP-1 signal induced by BFT stimulation, transfection with a dominant-negative c-Jun super-repressor was used. The dominant-negative $c$-Jun super-repressor almost completely suppressed AP-1 activity in HT-29 cells stimulated with BFT (Figure 4c). In this experimental system, transfection with the $c$-Jun superrepressor significantly reduced Lcn-2 promoter activation induced by BFT stimulation. Consistent with this, the levels of Lcn-2 mRNA and protein secretion induced by BFT resulted in significant inhibition when the AP-1 signal was blocked (Figure 4d). 
a Time after stimulation (h)

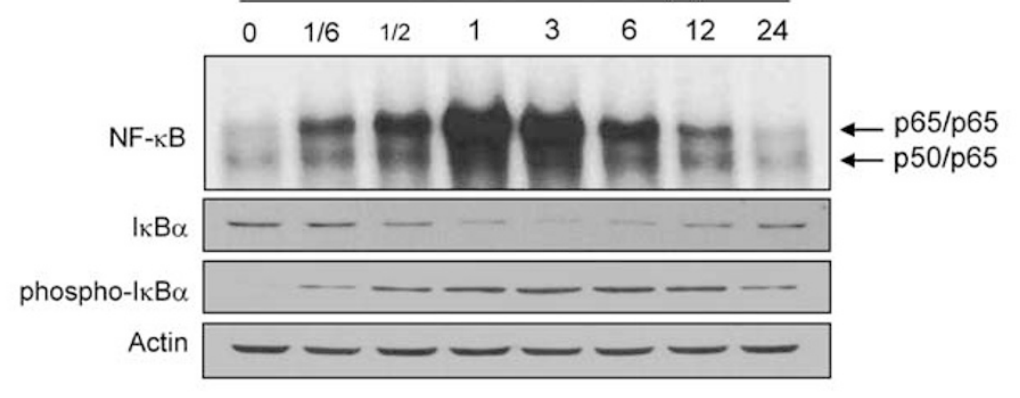

b
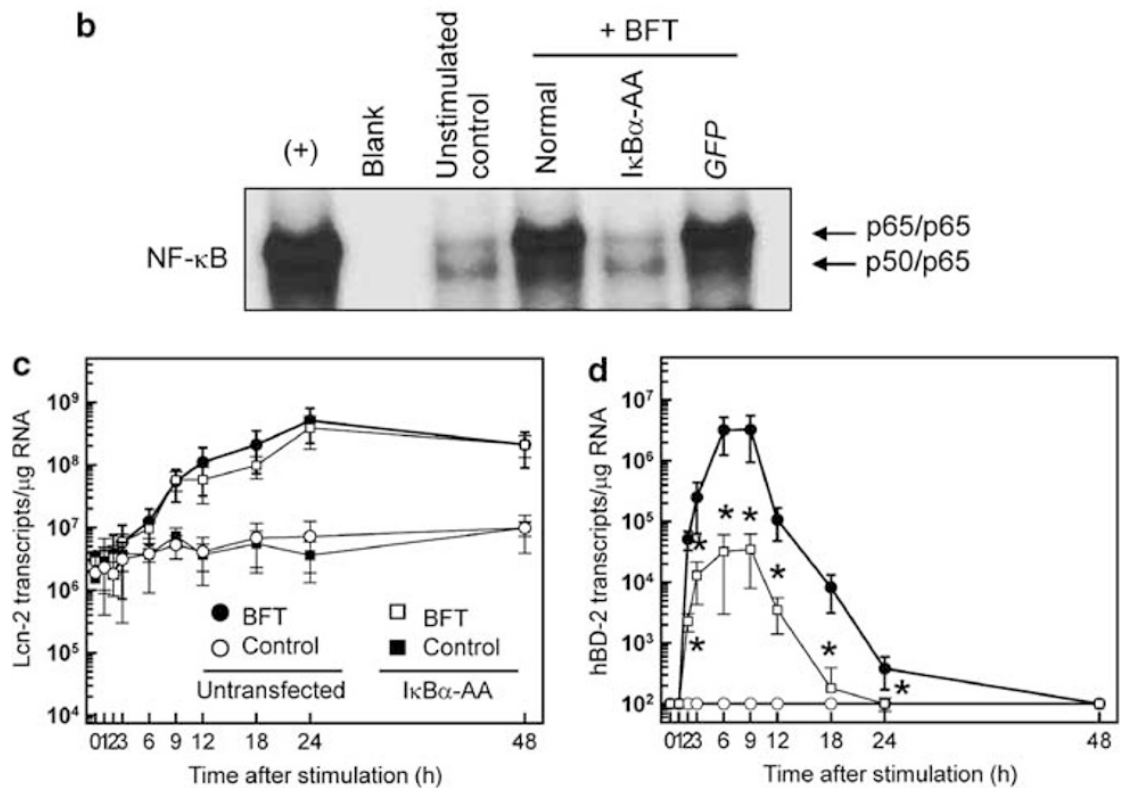

Figure 2 Relationship between NF- $\kappa$ B signaling and hBD-2 expression in BFT-stimulated HT-29 cells. (a) HT-29 cells were treated with BFT (100 ng/ml) for the indicated periods of time. NF- $\kappa$ B DNA binding activity was assessed by EMSA. Immunoblot results for concurrent $I \kappa B \alpha$, phospho-I $\kappa$ B $\alpha$, and actin expression levels in cells under the same conditions are provided beneath the EMSA. The results are representative of three independent experiments. (b) HT-29 cells were transfected with either retrovirus containing I $\kappa \mathrm{B} \alpha$-super-repressor (I $\kappa \mathrm{B} \alpha-\mathrm{AA})$ or control virus (GFP). At $48 \mathrm{~h}$ after transfection, the cells were stimulated with BFT $(100 \mathrm{ng} / \mathrm{ml})$ for $1 \mathrm{~h}$. NF- $\kappa$ B binding activity was assayed by EMSA. The $(+)$ symbol represents the positive control in which HT-29 cells were treated with TNF- $\alpha(20 \mathrm{ng} / \mathrm{ml})$. The results are representative of three repeated experiments. (c, d) Transfected or untransfected cells were treated with BFT $(100 \mathrm{ng} / \mathrm{ml})$ for $18 \mathrm{~h}(\mathbf{c}, \mathrm{Lcn}-2)$ or $6 \mathrm{~h}(\mathbf{d}, \mathrm{hBD}-2)$. Levels of Lcn-2 and hBD-2 mRNA were analyzed by quantitative RT-PCR using standard RNA. The values are expressed as the mean \pm s.d. $(n=5)$. The $\beta$-actin mRNA levels in each group remained relatively constant throughout the same period $\left(\sim 5 \times 10^{6}\right.$ transcripts/ $\mu$ g total RNA). In this experimental condition, Lcn-2 mRNA expressions in control virus (GFP)transfected cells in the presence or absence of BFT showed nonsignificant different from those of unstimulated control. ${ }^{*} P<0.05$ compared with untransfected cells treated with BFT.

To confirm the NF- $\kappa \mathrm{B}$-independent and AP-1-dependent expression of Lcn-2 in response to BFT stimulation, we performed another experiment using primary human intestinal epithelial cells. As shown in Figure 5a, the kinetics of NF- $\kappa \mathrm{B}$ signaling was quite different from those of AP-1 signaling. Activation of NF- $\kappa \mathrm{B}$ peaked $1 \mathrm{~h}$ after stimulation and decreased to baseline levels at $\sim 12 \mathrm{~h}$. In contrast, AP-1 activation peaked $\sim 1-6 \mathrm{~h}$ after stimulation and continued up to $24 \mathrm{~h}$. In this experimental system, pretreatment of primary intestinal epithelial cells with the AP-1 inhibitor SR11302 significantly reduced the Lcn-2 protein secretion in BFT-stimulated cells; however, a significant difference of Lcn-2 secretion was not observed between cells treated with an NF- $\kappa$ B inhibitor MG-132 + BFT and cells with BFT alone (Figure 5b). In contrast, the BFT-induced hBD-2 secretion was significantly inhibited by pretreatment with MG-132, but not with SR11302 (Figure 5c). These results indicate that AP-1 signaling plays a major role in the induction of Lcn-2 in BFT-stimulated intestinal epithelial cells.

\section{MAPKs Are Associated with Lcn-2 Induction in BFT-Stimulated Human Intestinal Epithelial Cells}

We next determined whether AP-1-induced Lcn-2 expression might be associated with MAPK signaling in intestinal epithelial cells stimulated with BFT. BFT strongly activated the phosphorylation of ERK1/2, p38, and JNK signals in HT-29 


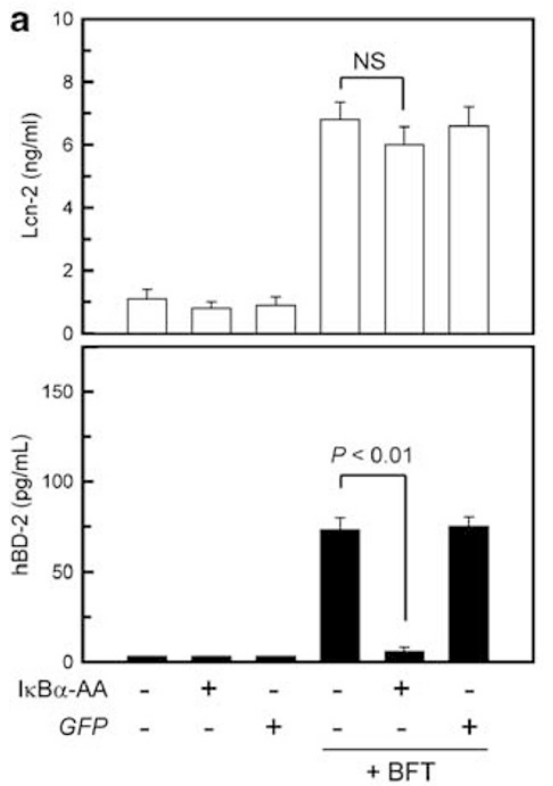

b

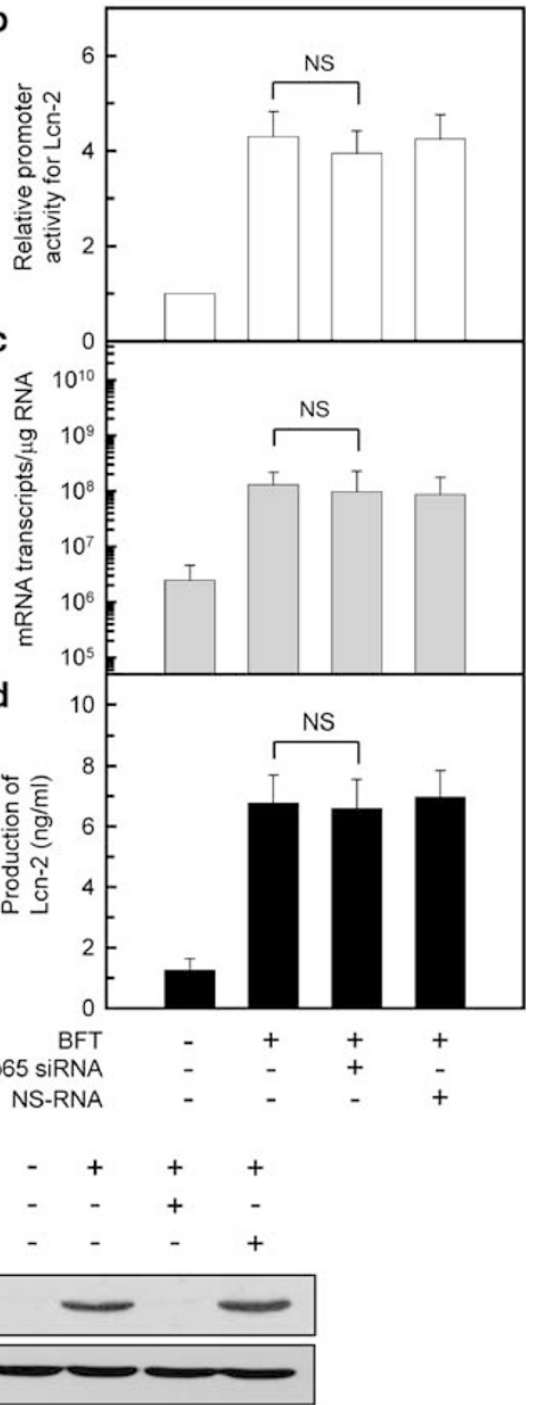

Figure 3 NF- $\kappa$ B-independent expression of Lcn-2 in BFT-stimulated HT-29 cells. (a) The culture and transfection conditions were the same as those described in the legend for Figure $2 \mathrm{c}$. Transfected or untransfected cells were treated with BFT $(100 \mathrm{ng} / \mathrm{ml})$ for $24 \mathrm{~h}$. The concentration of each protein in culture supernatants was determined by ELISA (mean \pm s.e.m., $n=5$ ). NS, statistically nonsignificant. (b) HT-29 cells were transfected with NF- $\kappa$ B p65-specific silencing siRNA (siRNA) or nonsilencing control siRNA (NS-RNA) for $48 \mathrm{~h}$, after which the transfected cells were cotransfected with a wild-type Lcn-2-luciferase transcriptional reporter. After $24 \mathrm{~h}$, the transfected cells were stimulated with BFT (100 $\mathrm{ng} / \mathrm{ml})$ for $18 \mathrm{~h}$. Data are expressed as mean fold induction \pm s.e.m. of luciferase activity relative to unstimulated controls $(n=5)$. The mean fold induction of the $\beta$-actin reporter gene relative to unstimulated controls remained relatively constant throughout each experiment. (c) NF- $\kappa$ B $p 65$ siRNA-transfected cells were stimulated with BFT $(100 \mathrm{ng} / \mathrm{ml})$ for $18 \mathrm{~h}$. Levels of Lcn-2 mRNA were analyzed by quantitative RT-PCR using standard RNA. The values are expressed as the mean \pm s.d. $(n=5)$. The $\beta$-actin mRNA levels in each group remained relatively constant throughout the same period $\left(\sim 10^{6}\right.$ transcripts/ $\mu \mathrm{g}$ total RNA). (d) NF- $\kappa \mathrm{B}$ p65 siRNA-transfected cells were stimulated with BFT $(100 \mathrm{ng} / \mathrm{ml})$ for $24 \mathrm{~h}$. The concentration of $\mathrm{Lcn}-2$ protein in culture supernatants was determined by ELISA (mean \pm s.e.m., $n=5$ ). (e) siRNA-transfected cells were combined with BFT $(100 \mathrm{ng} / \mathrm{ml}$ ) for $1 \mathrm{~h}$. Nuclear extracts were analyzed by immunoblotting with the indicated antibodies. Results shown are representative of three independent experiments.

cells. Activation of all three MAPK signaling molecules was first noted 10 min after stimulation (Figure 6a). To suppress each MAPK activity in BFT-stimulated cells, the following kinase inhibitors were used: PD98059, an inhibitor of MEK1/ 2, a MAPK that phosphorylates ERK1/2; pyridinyl imidazole SB203580, which specifically inhibits p38; and SP600125, which inhibits JNK. ${ }^{32}$ Pretreatment of HT-29 with PD98059 $(\geq 10 \mu \mathrm{M})$, SB203580 $(\geq 10 \mu \mathrm{M})$, or SP600125 $(\geq 50 \mu \mathrm{M})$ significantly inhibited the BFT-induced reporter gene activation of Lcn-2 (Figure 6b). In this experimental system, the ERK inhibitor and p38 inhibitor were superior to reducing Lcn-2 gene activation compared with the JNK inhibitor.

To further evaluate the relationship between MAPK activation and AP-1 induction in BFT-stimulated intestinal epithelial cells, we used a transfection model with recombinant adenoviruses. BFT-induced phosphorylation of ERK or p38 signals was suppressed in HT-29 cells infected 
a
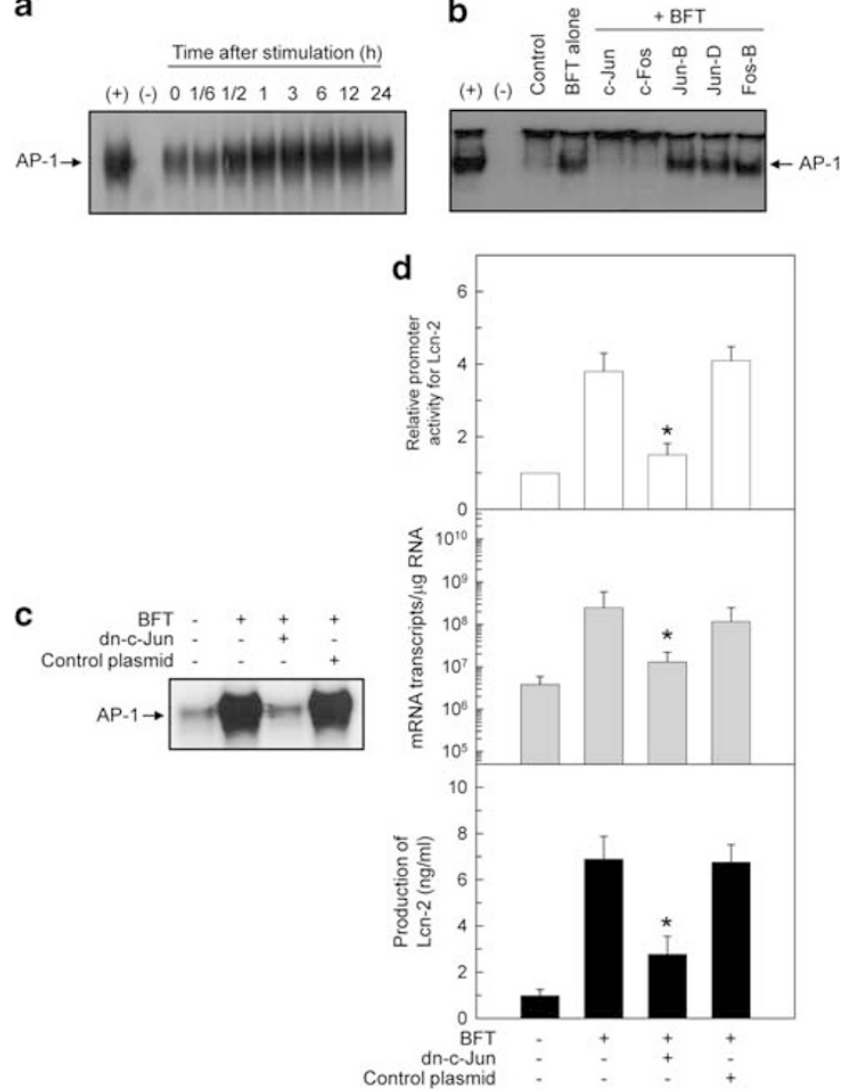

Figure 4 Effects of AP-1 inhibition on Lcn-2 expression in intestinal epithelial cells stimulated with BFT. (a) HT-29 cells were stimulated with BFT $(100 \mathrm{ng} / \mathrm{ml})$ for the indicated time periods. AP-1 activity was assessed by EMSA. The results are representative of three repeated experiments. (b) Supershift assays were performed using Abs to c-Jun, C-Fos, Jun B, Jun D, and Fos B in HT-29 cells stimulated with BFT for $2 \mathrm{~h}$. Results are representative of three independent experiments. (c) HT-29 cells were transfected with dominant-negative c-Jun super-repressor (dn-c-Jun) or control plasmid. Then, $48 \mathrm{~h}$ later, the cells were stimulated with BFT $(100 \mathrm{ng} / \mathrm{ml})$ for $2 \mathrm{~h}$ and EMSA was performed. The results are representative of three repeated experiments. (d) In the top panel, HT-29 cells were transfected with an Lcn-2-luciferase transcriptional reporter, together with the dominant-negative c-Jun super-repressor, as indicated. Then, $48 \mathrm{~h}$ later, the cells were stimulated with BFT $(100 \mathrm{ng} / \mathrm{ml})$ for $18 \mathrm{~h}$ and a luciferase assay was performed. Data are expressed as mean fold induction in luciferase activity relative to unstimulated controls \pm s.e.m. $(n=5)$. In the middle panel, dominant-negative c-Jun super-repressortransfected cells were stimulated with BFT $(100 \mathrm{ng} / \mathrm{ml})$ for $18 \mathrm{~h}$. Levels of Lcn-2 mRNA were analyzed by quantitative RT-PCR using standard RNA. The values are expressed as the mean \pm s.d. $(n=5)$. The $\beta$-actin mRNA levels in each group remained relatively constant throughout the same period ( $\sim 10^{6}$ transcripts/ $\mu \mathrm{g}$ total RNA). In the bottom panel, dominantnegative c-Jun super-repressor-transfected cells were stimulated with BFT $(100 \mathrm{ng} / \mathrm{ml})$ for $24 \mathrm{~h}$. The concentration of Lcn-2 protein in culture supernatants was determined by ELISA (mean \pm s.e.m., $n=5$ ). ${ }^{*} P<0.05$ compared with BFT alone.

with the corresponding recombinant adenovirus to control levels (Figure $6 \mathrm{c}$ ). In this experimental condition, transfection with expression vectors containing dominant-negative mutants significantly decreased the activation of AP-1
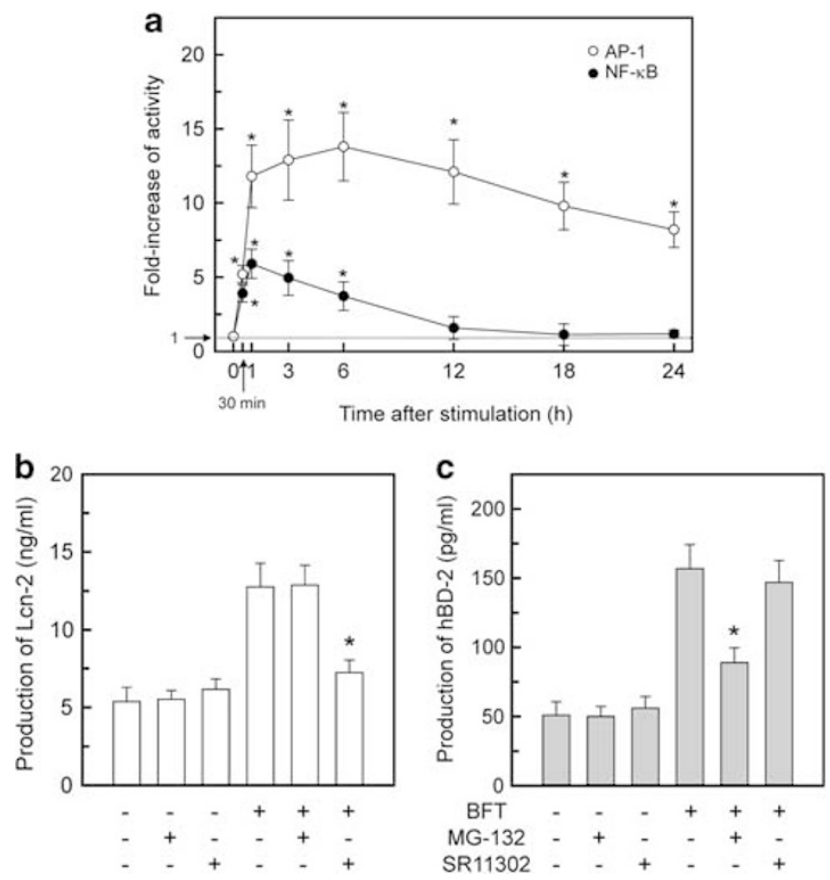

Figure 5 Relationship between the suppression of NF- $\kappa$ B or AP-1 activity and Lcn-2 production in primary human intestinal epithelial cells stimulated with BFT. (a) Primary human intestinal epithelial cells were stimulated with BFT $(100 \mathrm{ng} / \mathrm{ml})$ for the indicated periods. Activities of $\mathrm{NF}-\kappa \mathrm{B}$ (closed circle) and AP-1 (open circle) were measured by ELISA kits. Data are expressed as the mean fold induction \pm s.e.m. relative to untreated controls $(n=3)$. Asterisks indicate values that are significantly different from those of the control $(P<0.05)$. (b, c) Primary intestinal epithelial cells were preincubated with the NF- $\kappa$ B inhibitor MG-132 $(50 \mu \mathrm{M})$ or the AP-1 inhibitor SR11302 $(10 \mu \mathrm{M})$ for 30 min and then stimulated with BFT $(100 \mathrm{ng} / \mathrm{ml})$ for another $24 \mathrm{~h}$. The concentration of Lcn-2 or hBD-2 protein in culture supernatants was determined by ELISA (mean \pm s.e.m., $n=3$ ). ${ }^{*} P<0.05$ compared with BFT alone.

following BFT stimulation. Concurrently, transfection with adenovirus containing dominant-negative expression vectors significantly inhibited Lcn-2 promoter activity in BFT-stimulated cells (Figure 6d).

To confirm the ability of BFT to induce MAPK- and AP-1dependent Lcn-2 expression in a cell line model, we performed experiments using isolated primary human intestinal epithelial cells. Cells were treated with BFT and ELISA was used to measure phosphorylation activity of each MAPK signal. Maximum activation of all three MAPKs was observed after $60 \mathrm{~min}$, which then subsequently decreased (Figure 7a). Notably, phospho-JNK activity reached the control level within $6 \mathrm{~h}$ after stimulation; however, BFT-induced activation of ERK and p38 was sustained for the entire experimental period. Considering that the increased Lcn-2 mRNA expression was first observed $9 \mathrm{~h}$ after stimulation (Figure 1a), JNK signaling seems not to be involved in Lcn-2 expression in response to BFT stimulation. In this experimental condition, primary intestinal epithelial cells were pretreated with each MAPK inhibitor and then stimulated with BFT. Pretreatment with MAPK inhibitors such as 

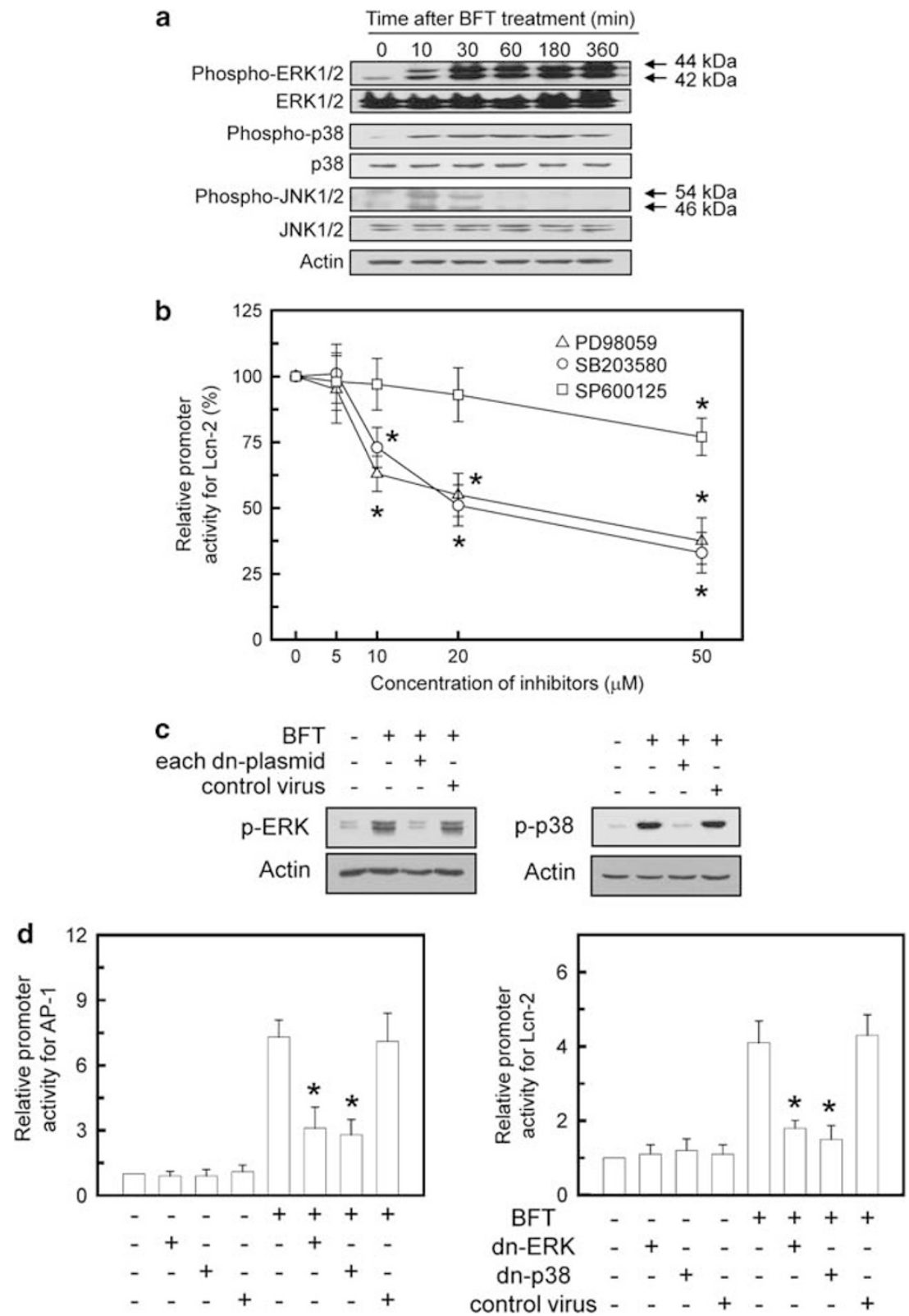

Figure 6 Relationship between MAPK signals and Lcn-2 expression in BFT-stimulated HT-29 cells. (a) HT-29 cells were stimulated with BFT (100 ng/ml) for the indicated time periods. ERK1/2, p38, and JNK activities were measured by immunoblot analysis. Results are representative of three independent experiments. (b) HT-29 cells were transfected with an Lcn-2-luciferase transcriptional reporter for $24 \mathrm{~h}$. The transfected cells were preincubated with PD98059 (open triangle), SB203580 (open circle), or SP600125 (open square) for $30 \mathrm{~min}$, and then stimulated with BFT (100 ng/ml) for another $18 \mathrm{~h}$. Data are expressed as the mean $\%$ induction in luciferase activity relative to unstimulated controls \pm s.e.m. $(n=5)$. ${ }^{*} P<0.05$ compared with BFT alone. (c) HT-29 cells were transfected with adenovirus containing dominant-negative ERK (dn-JNK) or p38 (dn-p38) expression vectors. Then, $48 \mathrm{~h}$ after transfection, cells were stimulated with BFT $(100 \mathrm{ng} / \mathrm{ml})$ for $1 \mathrm{~h}$. Phosphorylated p38 and JNK in cell extracts were analyzed by immunoblotting with the indicated antibodies. Results shown are representative of three independent experiments. (d) HT-29 cells were transfected with an AP-1-luciferase or an Lcn-2-luciferase transcriptional reporter, together with adenovirus containing dominant-negative ERK (dn-ERK) or p38 (dn-p38) expression vectors, as indicated. Then, $48 \mathrm{~h}$ later, cells were stimulated with BFT (100 ng/ml) for $3 \mathrm{~h} \mathrm{(AP-1)} \mathrm{or} 18 \mathrm{~h} \mathrm{(Lcn-2)} \mathrm{and} \mathrm{a} \mathrm{luciferase} \mathrm{assay} \mathrm{was} \mathrm{performed.} \mathrm{Data} \mathrm{are}$ expressed as the mean fold induction in luciferase activity relative to nonstimulated controls \pm s.e.m. $(n=5)$. ${ }^{*} P<0.05$ compared with BFT alone.

PD98059 and SB203580 significantly reduced the levels of AP-1 induced by BFT (Figure 7b). In addition, MAPK inhibitors significantly attenuated the production of Lcn-2 protein compared with the control under BFT-stimulated conditions (Figure 7c). However, pretreatment with JNK inhibitor SP600125 $(20 \mu \mathrm{M})$ did not significantly affect the BFT-induced Lcn-2 protein secretion compared with BFT alone (unstimulated control, $5.76 \pm 0.94 \mathrm{ng} / \mathrm{ml}$; BFT alone, $13.81 \pm 2.51 \mathrm{ng} / \mathrm{ml} ; \quad J N K+B F T, 12.55 \pm 3.67 \mathrm{ng} / \mathrm{ml}$; mean \pm s.e.m., $n=3$ ). In these experiments, DMSO was used to 

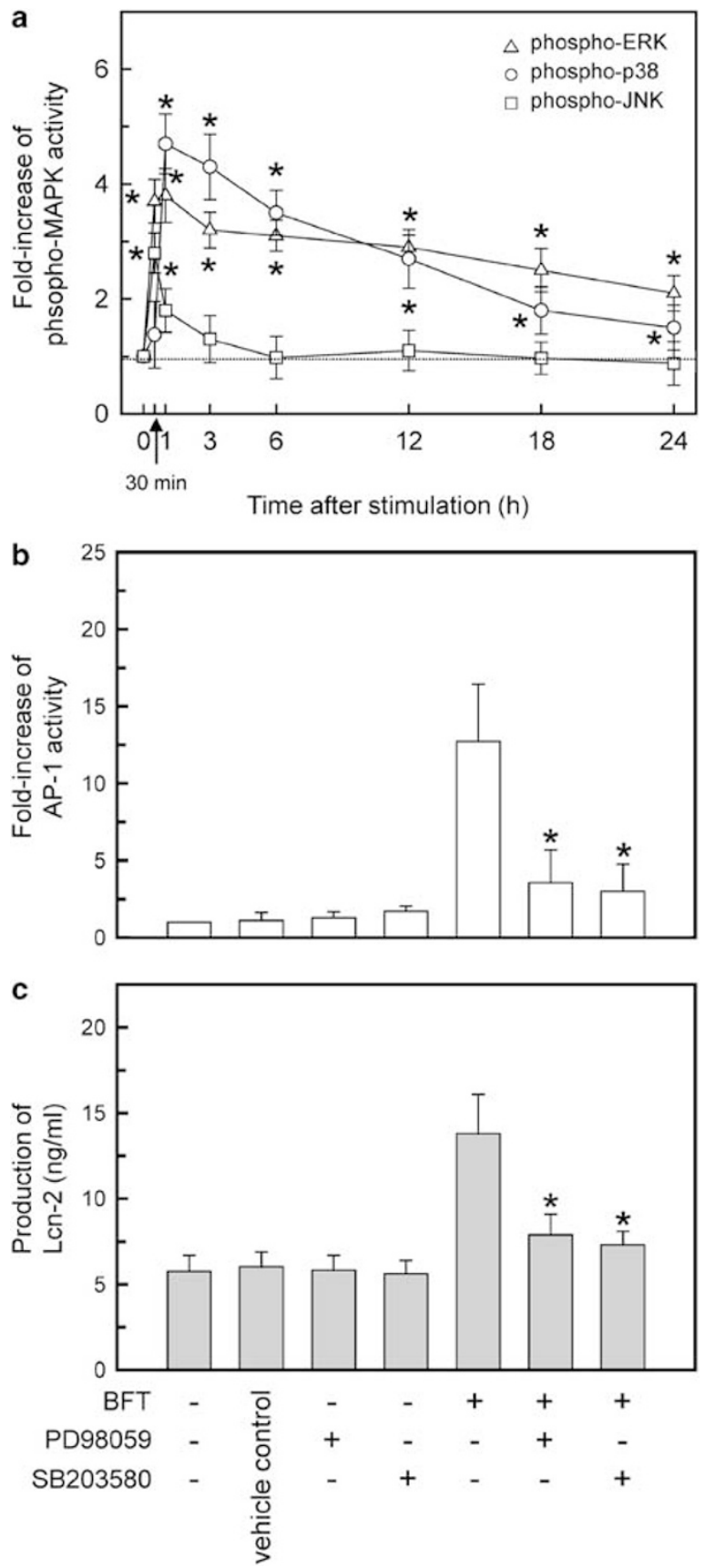

Figure 7 MAPK signals are associated with Lcn-2 expression in BFTstimulated primary human intestinal epithelial cells. (a) Primary human intestinal epithelial cells were stimulated with BFT $(100 \mathrm{ng} / \mathrm{ml})$ for the indicated periods. Activities of phospho-ERK (open triangle), phospho-p38 (open circle), or phospho-JNK (open square) were measured by ELISA kits. Data are expressed as the mean fold induction \pm s.e.m. relative to untreated controls $(n=3)$. Asterisks indicate values that are significantly different from those of the control $(P<0.05)$. (b, c) Primary intestinal epithelial cells were preincubated with PD98059 $(20 \mu \mathrm{M})$ or SB203580 $(20 \mu \mathrm{M})$ for $30 \mathrm{~min}$, and then stimulated with BFT (100 ng/ml) for another $1 \mathrm{~h}$ (AP-1) or $24 \mathrm{~h}(\mathrm{Lcn}-2)$. AP-1 activity (b, the mean fold induction \pm s.e.m. relative to untreated controls, $n=3$ ) and of Lcn-2 protein secretion (c, the mean \pm s.e.m., $n=3$ ) were measured by each ELISA kit. The data of vehicle control were obtained from cells treated with $0.1 \%$ DMSO alone. Asterisks indicate values that are significantly different from those of BFT alone $(P<0.05)$. dissolve MAPK inhibitors and the concentration of DMSO in culture media was $<0.1 \%$. The addition of $0.1 \%$ DMSO to culture media did not influence the Lcn-2 production in controls.

\section{Polarized Secretion of Lcn-2 in Response to BFT Stimulation}

Intestinal epithelial cells are structurally and functionally polarized in vivo. If antimicrobial Lcn-2 produced by BFTstimulated intestinal epithelial cells plays a physiologic role for the bacteria on the intestinal lumen, Lcn-2 would predictably be released from the apical surface of infected epithelial cells. The T84 cells form polarized barriers with high levels of TER ( $>1000 \Omega \times \mathrm{cm}^{2}$ ) when grown on transwells. In addition, the $\left[{ }^{3} \mathrm{H}\right]$-inulin flux across T84 monolayers was measured because T84 monolayers are highly selective to the passage of small molecules such as radioisotope tracers. As shown in Figure 8a, T84 cells formed stable barriers day 12 after seeding and maintained a strict barrier. In this experimental condition, the apical stimulation of T84 cells with BFT resulted in a marked induction in Lcn-2 expression, of which $\sim 66 \%$ of Lcn-2 was found in the apical compartment, whereas IL-8 was released predominantly into the basolateral compartment. In addition, T84 cells stimulated with BFT secreted significant amounts of $\mathrm{Lcn}-2$ protein into the basolateral compartments (Figure $8 \mathrm{~b}$ ). These results indicate that the secretion of Lcn-2 in BFT-stimulated intestinal epithelial cells may occur from both apical and basolateral surfaces.

\section{DISCUSSION}

One of the strategies for controlling colonization of unwanted intestinal microbes is to limit iron availability in the gut. To overcome this defense mechanism, some bacteria release siderophores that can remove iron from host proteins and are subsequently taken up by specialized bacterial transport systems. ${ }^{43}$ However, host cells can secrete Lcn-2 protein that binds ferric siderophore complexes, preventing bacteria from acquiring iron. In the present study, we found that one of the inflammatory responses to ETBF-derived BFT was the upregulation of Lcn-2 expression in intestinal epithelial cells through the activation of MAPK and AP-1 pathways.

Lcn-2 induction seems to be a relatively late response of intestinal epithelial cells to BFT stimulation compared with hBD-2 expression. Thus, the expression of Lcn-2 transcripts was first apparent $9 \mathrm{~h}$ after BFT stimulation and continued to increase over the next $48 \mathrm{~h}$. In contrast, expression of hBD-2 mRNA was noted $2 \mathrm{~h}$ after stimulation and returned to control levels within $24 \mathrm{~h}^{10}$ We assumed that kinetic differences for the induction of each antimicrobial factor may be because of differential activation of each promoter under BFT-stimulated conditions, and we attempted to verify this hypothesis. 

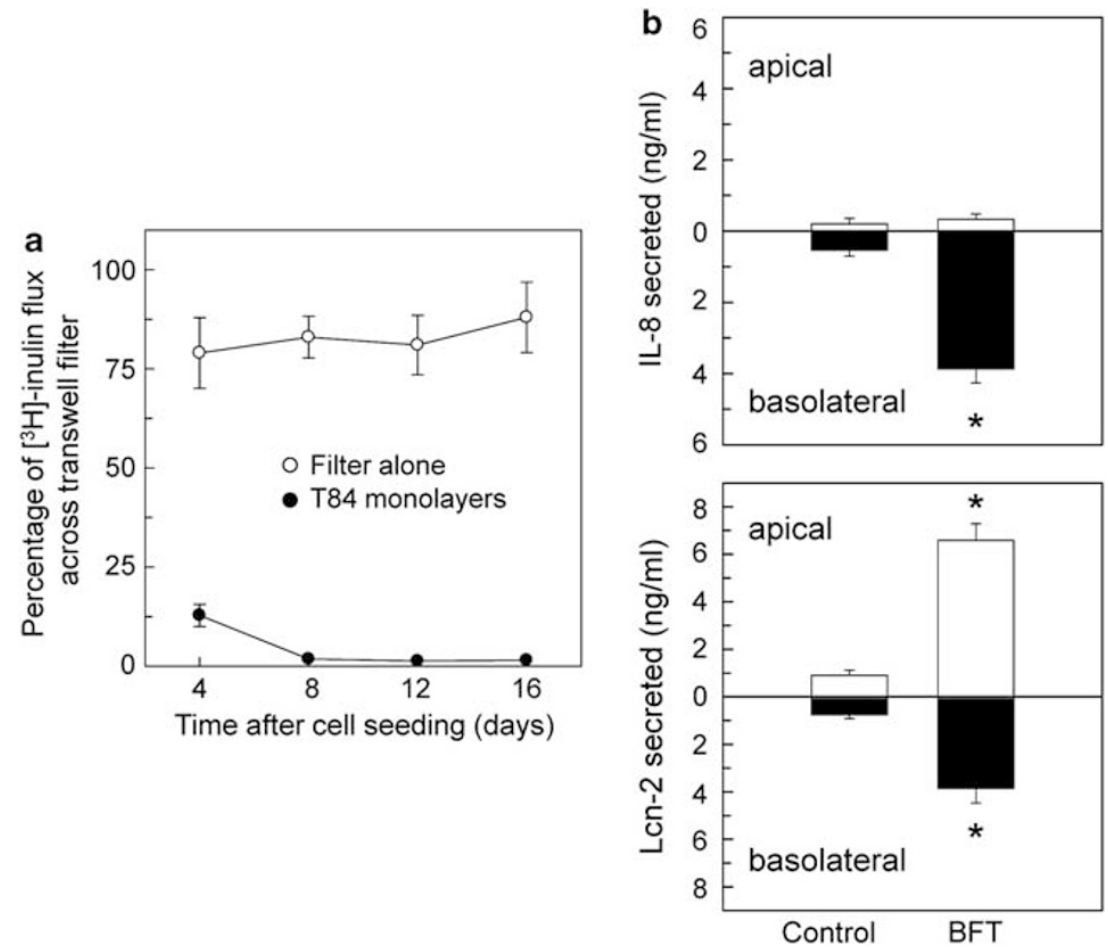

Figure 8 Polarized secretion of Lcn-2 and IL-8 released by T84 cells. (a) Measurement of $\left[{ }^{3} \mathrm{H}\right]$-inulin flux across the T84 monolayers. T84 cells were grown in the transwell chamber for the indicated days. Numbers of counts per min (c.p.m.) were measured in the bottom well as described in the Materials and methods. For measurement of equilibration of radioactivity in the absence of a barrier, transwells without T84 cells were used (filter alone). Data are presented as percentage of $\left[{ }^{3} \mathrm{H}\right]$-inulin flux by calculating the counted c.p.m. divided by the total number of c.p.m. added to the top chamber (mean \pm s.e.m., $n=3$ ). (b) Polarized monolayers of T84 cells in transwell were stimulated with BFT ( $100 \mathrm{ng} / \mathrm{ml})$ for $24 \mathrm{~h}$ and the supernatants were obtained from the upper and lower chambers. Lcn-2 secretion was determined by ELISA. Data are shown as the mean \pm s.e.m. ( $n=5)$. ${ }^{*} P<0.05$ compared with control.

Transcriptional factors such as NF- $\kappa \mathrm{B}$ and AP-1 regulate a variety of inflammatory responses. ${ }^{44}$ The promoter regions of the Lcn-2 and hBD-2 genes contain binding sites for both NF- $\kappa$ B and AP-1. Thus, the induction of Lcn- 2 or hBD-2 by cytokines or bacteria requires the activation of NF- $\kappa \mathrm{B}$ and/or AP-1 and their binding to the promoter region. In the present study, exposure of intestinal epithelial cells with BFT strongly activated both NF- $\kappa \mathrm{B}$ and AP-1 signals. These transcription factors were activated within 10-30 min of stimulation, but the kinetics of the activation were quite different. The activating signals of NF- $\kappa \mathrm{B}$ in primary human intestinal epithelial cells continued $6 \mathrm{~h}$ after stimulation and recovered to basal levels within $\sim 12 \mathrm{~h}$; however, AP-1 activating signals remained $24 \mathrm{~h}$ after stimulation. In this experimental system, suppression of AP-1 activity significantly inhibited BFTinduced Lcn- 2 expression. In contrast, suppression of NF- $\kappa \mathrm{B}$ activity did not result in a significant change in BFT-induced Lcn-2 expression. The AP-1-dependent and NF- $\kappa \mathrm{B}-$ independent induction of $\mathrm{Lcn}-2$ is quite different from hBD-2 expression in intestinal epithelial cells exposed to ETBF-derived BFT. Thus, the induction of hBD-2 expression was mediated through an NF- $\kappa \mathrm{B}$-dependent and AP-1independent pathway in BFT-stimulated intestinal epithelial cells. ${ }^{10}$ Therefore, a relatively late induction of $\mathrm{Lcn}-2$ compared with hBD-2 may be in part because of activation kinetics between NF- $\kappa \mathrm{B}$ and AP-1 signals in response to BFT stimulation.

MAPK signaling in intestinal epithelial cells is known to be an important event in response to BFT stimulation. ${ }^{10,26,27,31}$ However, no report has shown that the cooperation between AP-1 and MAPK signaling may be related to Lcn-2 induction in BFT-stimulated cells. To gain insight into the signaling pathway, we attempted to determine whether MAPK signaling was associated with AP-1-dependent expression of Lcn-2. In the present study, inhibition of MAPK signals resulted in the significant suppression of AP-1 activity and Lcn-2 expression in BFT-stimulated cells. In addition, the suppression of ERK and p38 signals seems to be superior to the JNK in the inhibition of Lcn-2 expression. The limited relevance of JNK to Lcn-2 expression in BFT-exposed cells may be in part because of the kinetics of activated JNK signals. Thus, BFT-induced JNK signals almost disappeared $6 \mathrm{~h}$ after stimulation but both activated signals of ERK and p38 were sustained until $24 \mathrm{~h}$ after stimulation in primary intestinal epithelial cells. Moreover, Lcn-2 upregulation may be a relatively late response of the intestinal epithelial cells to BFT stimulation. These results enabled us to reach the conclusion that the different kinetics in each MAPK may in 
turn lead to the unique Lcn-2 upregulation in BFTstimulated intestinal epithelial cells.

We already demonstrated that the suppression of JNK activity in intestinal epithelial cells did not significantly affect $\mathrm{hBD}-2$ expression induced by BFT stimulation. ${ }^{10}$ In addition, the induction of hBD-2 was mediated through an NF- $\kappa \mathrm{B}$-dependent and AP-1-independent pathway in BFT-stimulated cells. In the present study, BFT-induced JNK signals sustained for a relatively short period of time. Therefore, the activated JNK signaling seems not to result in the NF- $\kappa \mathrm{B}$ activation enough to produce a detectable amount of hBD-2 protein in intestinal epithelial cells under BFT-stimulated condition. However, further study should be needed to clarify the relationship between JNK signals and hBD-2 production in BFT-stimulated intestinal epithelial cells.

In the present study, ERK1/2 and p38 signals were associated with AP-1 activation in response to BTF stimulation. As the p38 and ERK kinases are known to be involved in the control of c-jun and c-fos promoters, ${ }^{45-47}$ activated p38 and ERK signals may lead to the activation of c-jun and c-fos promoters in BFT-exposed intestinal epithelial cells. Nevertheless, further studies are required to clarify the signaling that may contribute to the MAPK-induced AP-1 activation in BFT-stimulated intestinal epithelial cells.

The secretion of Lcn-2 in BFT-stimulated intestinal epithelial cells occurred from the apical and basolateral surfaces of cells. Considering that Lcn-2 specifically binds enterochelin, which results in a bacteriostatic activity for some commensal bacteria such as E. coli, ${ }^{17,48,49}$ the apical secretion of Lcn-2 can affect bacterial growth within the intestinal lumen. However, B. fragilis utilizes outer membrane proteins for the acquisition of iron from heme-compounds present in normal serum, indicating that iron chelators are rarely used in B. fragilis. ${ }^{50-52}$ Therefore, the apical secretion of Lcn-2 by BFT may play a role in the growth inhibition of other bacterial groups except $B$. fragilis.

In summary, we demonstrated that the exposure of intestinal epithelial cells to BFT results in the activation of a signaling cascade, including MAPK and AP-1, and subsequent Lcn-2 expression.

\section{ACKNOWLEDGEMENTS}

This research was supported by Basic Science Research Program through the National Research Foundation of Korea (NRF) funded by the Ministry of Education, Science and Technology (MEST) (No. 2010-0008594) and a grant from the NRF of Korea Grant funded by the Korean Government (MEST) (MRC Program No. 2010-0029507). We thank Dr Martin F Kagnoff for providing several plasmids ( $2 \times \mathrm{pNF}-\kappa \mathrm{B}-, \mathrm{p} \beta$-actin- and $\mathrm{pRSV}-\beta$ galactosidase-luciferase plasmids, and standard RNA for human $\beta$-actin), Dr Tatsushi Muta for the pNGAL(-900)-luc plasmid, Dr Jürgen Harder for the hBD-2-2338-luc plasmid, and Dr Andreas von Knethen for the TAM-67 plasmid.

\section{DISCLOSURE/CONFLICT OF INTEREST}

The authors declare no conflict of interest.
1. Prindiville TP, Sheikh RA, Cohen $\mathrm{SH}$, et al. Bacteroides fragilis enterotoxin gene sequences in patients with inflammatory bowel disease. Emerg Infect Dis 2000;6:171-174.

2. Sears $\mathrm{CL}$, Islam $\mathrm{S}$, Saha $A$, et al. Association of enterotoxigenic Bacteroides fragilis infection with inflammatory diarrhea. Clin Infect Dis 2008;47:797-803.

3. Toprak NU, Yagci A, Gulluoglu BM, et al. A possible role of Bacteroides fragilis enterotoxin in the aetiology of colorectal cancer. Clin Microbiol Infect 2006;12:782-786.

4. Wu S, Rhee $\mathrm{KJ}$, Albesiano $\mathrm{E}$, et al. A human colonic commensal promotes colon tumorigenesis via activation of $\mathrm{T}$ helper type $17 \mathrm{~T}$ cell responses. Nat Med 2009;15:1016-1022.

5. Sears CL. Enterotoxigenic Bacteroides fragilis: a rogue among symbiotes. Clin Microbiol Rev 2009;22:349-369.

6. Cash $\mathrm{HL}$, Whitham $\mathrm{CV}$, Behrendt $\mathrm{CL}$, et al. Symbiotic bacteria direct expression of an intestinal bactericidal lectin. Science 2006;313: 1126-1130.

7. Howell SJ, Wilk D, Yadav SP, et al. Antimicrobial polypeptides of the human colonic epithelium. Peptides 2003;24:1763-1770.

8. Nuding S, Zabel LT, Enders C, et al. Antibacterial activity of human defensins on anaerobic intestinal bacterial species: a major role of HBD-3. Microbes Infect 2009;11:384-393.

9. Tollin M, Bergman P, Svenberg $T$, et al. Antimicrobial peptides in the first line defence of human colon mucosa. Peptides 2003;24:523-530.

10. Yoon YM, Lee JY, Yoo D, et al. Bacteroides fragilis enterotoxin induces human beta-defensin-2 expression in intestinal epithelial cells via a mitogen-activated protein kinase/lkappaB kinase/NF-kappaBdependent pathway. Infect Immun 2010;78:2024-2033.

11. Sears CL. The toxins of Bacteroides fragilis. Toxicon 2001;39:1737-1746.

12. Sears $\mathrm{CL}$, Myers LL, Lazenby $\mathrm{A}$, et al. Enterotoxigenic Bacteroides fragilis. Clin Infect Dis 1995;20(Suppl 2):S142-S148.

13. Nakano V, Gomes DA, Arantes RM, et al. Evaluation of the pathogenicity of the Bacteroides fragilis toxin gene subtypes in gnotobiotic mice. Curr Microbiol 2006;53:113-117.

14. Rhee $\mathrm{KJ}, \mathrm{Wu} \mathrm{S}, \mathrm{Wu} \mathrm{X}$, et al. Induction of persistent colitis by a human commensal, enterotoxigenic Bacteroides fragilis, in wild-type C57BL/6 mice. Infect Immun 2009;77:1708-1718.

15. Rabizadeh S, Rhee KJ, Wu S, et al. Enterotoxigenic Bacteroides fragilis: a potential instigator of colitis. Inflamm Bowel Dis 2007;13:1475-1483.

16. Miethke M, Skerra A. Neutrophil gelatinase-associated lipocalin expresses antimicrobial activity by interfering with L-norepinephrinemediated bacterial iron acquisition. Antimicrob Agents Chemother 2010;54:1580-1589.

17. Flo TH, Smith KD, Sato $S$, et al. Lipocalin 2 mediates an innate immune response to bacterial infection by sequestrating iron. Nature 2004;432:917-921.

18. Chan YR, Liu JS, Pociask DA, et al. Lipocalin 2 is required for pulmonary host defense against Klebsiella infection. J Immunol 2009;182: 4947-4956.

19. Fischbach MA, Lin $H$, Zhou $L$, et al. The pathogen-associated iroA gene cluster mediates bacterial evasion of lipocalin 2. Proc Natl Acad Sci USA 2006;103:16502-16507.

20. Li C, Chan YR. Lipocalin 2 regulation and its complex role in inflammation and cancer. Cytokine 2011;56:435-441.

21. Cowland JB, Sørensen OE, Sehested M, et al. Neutrophil gelatinaseassociated lipocalin is up-regulated in human epithelial cells by IL-1 beta, but not by TNF-alpha. J Immunol 2003;171:6630-6639.

22. Gwira JA, Wei F, Ishibe $S$, et al. Expression of neutrophil gelatinaseassociated lipocalin regulates epithelial morphogenesis in vitro. J Biol Chem 2005;280:7875-7882.

23. Hanai J, Mammoto $\mathrm{T}$, Seth $\mathrm{P}$, et al. Lipocalin 2 diminishes invasiveness and metastasis of Ras-transformed cells. J Biol Chem 2005;280: 13641-13647.

24. Matsuo $\mathrm{S}$, Yamazaki S, Takeshige $\mathrm{K}$, et al. Crucial roles of binding sites for NF-kappaB and C/EBPs in IkappaB-zeta-mediated transcriptional activation. Biochem J 2007;405:605-615.

25. Kim JM, Lee DH, Kim JS, et al. 5,7-dihydroxy-3,4,6-trimethoxyflavone inhibits the inflammatory effects induced by Bacteroides fragilis enterotoxin via dissociating the complex of heat shock protein 90 and IkappaB alpha and IkappaB kinase-gamma in intestinal epithelial cell culture. Clin Exp Immunol 2009;155:541-551.

26. Kim JM, Jung HY, Lee JY, et al. Mitogen-activated protein kinase and activator protein-1 dependent signals are essential for Bacteroides 
fragilis enterotoxin-induced enteritis. Eur J Immunol 2005;35: 2648-2657.

27. Kim JM, Lee JY, Kim YJ. Inhibition of apoptosis in Bacteroides fragilis enterotoxin-stimulated intestinal epithelial cells through the induction of c-IAP-2. Eur J Immunol 2008;38:2190-2199.

28. Kim JM, Lee JY, Yoon YM, et al. Bacteroides fragilis enterotoxin induces cyclooxygenase- 2 and fluid secretion in intestinal epithelial cells through NF-kappaB activation. Eur J Immunol 2006;36:2446-2456.

29. Kim JM, Cho SJ, Oh YK, et al. Nuclear factor-kappa B activation pathway in intestinal epithelial cells is a major regulator of chemokine gene expression and neutrophil migration induced by Bacteroides fragilis enterotoxin. Clin Exp Immunol 2002;130:59-66.

30. Kim JM, Oh YK, Kim YJ, et al. Polarized secretion of CXC chemokines by human intestinal epithelial cells in response to Bacteroides fragilis enterotoxin: NF-kappa B plays a major role in the regulation of IL-8 expression. Clin Exp Immunol 2001;123:421-427.

31. Wu S, Powell J, Mathioudakis $\mathrm{N}$, et al. Bacteroides fragilis enterotoxin induces intestinal epithelial cell secretion of interleukin- 8 through mitogen-activated protein kinases and a tyrosine kinase-regulated nuclear factor-kappaB pathway. Infect Immun 2004;72:5832-5839.

32. Huang C, Ma WY, Dawson Ml, et al. Blocking activator protein-1 activity, but not activating retinoic acid response element, is required for the antitumor promotion effect of retinoic acid. Proc Natl Acad Sci USA 1997;94:5826-5830.

33. Roh HC, Yoo DY, Ko SH, et al. Bacteroides fragilis enterotoxin upregulates intercellular adhesion molecule-1 in endothelial cells via an aldose reductase-, MAPK-, and NF-кB-dependent pathway, leading to monocyte adhesion to endothelial cells. J Immunol 2011;187:1931-1941.

34. Hurley BP, Sin A, McCormick BA. Adhesion molecules involved in hepoxilin A3-mediated neutrophil transepithelial migration. Clin Exp Immunol 2008;151:297-305.

35. Kim JM, Kim JS, Jung HC, et al. Helicobacter pylori infection activates NF-kappaB signaling pathway to induce iNOS and protect human gastric epithelial cells from apoptosis. Am J Physiol Gastrointest Liver Physiol 2003;285:G1171-G1180.

36. Lee JY, Park HR, Oh YK, et al. Effects of transcription factor activator protein-1 on interleukin-8 expression and enteritis in response to Clostridium difficile toxin A. J Mol Med 2007;85:1393-1404.

37. Park H, Kim NI, Kim JM, et al. Expression of eotaxin in gastric epithelial cells stimulated with Helicobacter pylori vacuolating cytotoxin. J Bacteriol Virol 2006;36:11-20.

38. Wehkamp K, Schwichtenberg L, Schröder JM, et al. Pseudomonas aeruginosa- and IL-1beta-mediated induction of human beta-defensin-2 in keratinocytes is controlled by NF-kappaB and AP-1. J Invest Dermatol 2006;126:121-127.

39. Elewaut D, DiDonato JA, Kim JM, et al. NF-kappa B is a central regulator of the intestinal epithelial cell innate immune response induced by infection with enteroinvasive bacteria. J Immunol 1999;163:1457-1466.

40. Brown PH, Alani R, Preis LH, et al. Suppression of oncogene-induced transformation by a deletion mutant of c-jun. Oncogene 1993;8:877-886.

41. Kim JM, Kim JS, Kim YJ, et al. Conjugated linoleic acids produced by Lactobacillus dissociates IKK-gamma and Hsp90 complex in Helicobacter pylori-infected gastric epithelial cells. Lab Invest 2008;88: 541-552.

42. Lee JY, Kim H, Cha MY, et al. Clostridium difficile toxin A promotes dendritic cell maturation and chemokine CXCL2 expression through p38, IKK, and the NF-kappaB signaling pathway. J Mol Med 2009; 87:169-180.

43. Raffatellu $M$, George $M D$, Akiyama $Y$, et al. Lipocalin-2 resistance confers an advantage to Salmonella enterica serotype Typhimurium for growth and survival in the inflamed intestine. Cell Host Microbe 2009;5:476-486.

44. Yuk JM, Jo EK. Toll-like receptors and innate immunity. J Bacteriol Virol 2011;41:225-235.

45. Lopez-Bergami P, Lau E, Ronai Z. Emerging roles of ATF2 and the dynamic AP1 network in cancer. Nat Rev Cancer 2010;10:65-76.

46. Backert S, Naumann M. What a disorder: proinflammatory signaling pathways induced by Helicobacter pylori. Trends Microbiol 2010;18: 479-486.

47. Manzoor $Z$, Koh YS. Mitogen-activated protein kinases in inflammation. J Bacteriol Virol 2012;42:189-195.

48. Berger T, Togawa A, Duncan GS, et al. Lipocalin 2-deficient mice exhibit increased sensitivity to Escherichia coli infection but not to ischemiareperfusion injury. Proc Natl Acad Sci USA 2006;103:1834-1839.

49. Goetz DH, Holmes MA, Borregaard N, et al. The neutrophil lipocalin NGAL is a bacteriostatic agent that interferes with siderophoremediated iron acquisition. Mol Cell 2002;10:1033-1043.

50. Otto BR, Sparrius M, Verweij-van Vught AM, et al. Iron-regulated outer membrane protein of Bacteroides fragilis involved in heme uptake. Infect Immun 1990;58:3954-3958.

51. Otto BR, Verweij-van Vught AM, MacLaren DM. Transferrins and hemecompounds as iron sources for pathogenic bacteria. Crit Rev Microbiol 1992;18:217-233.

52. Sijbrandi R, Den Blaauwen T, Tame JR, et al. Characterization of an iron-regulated alpha-enolase of Bacteroides fragilis. Microbes Infect 2005;7:9-18. 